\title{
Health-state utilities in a prisoner population: a cross-sectional
}

\section{survey}

\author{
Christopher AKY Chong*1,2, Sicong Li ${ }^{3}$, Geoffrey C Nguyen4,5, \\ Andrew Sutton6, Michael H Levy ${ }^{7}$, Tony Butler7,8, Murray D Krahn ${ }^{2,9}$ and \\ Hla-Hla Thein ${ }^{10}$
}

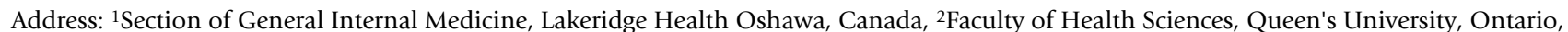
Canada, ${ }^{3}$ Faculty of Pharmacy, University of Toronto, Toronto, Ontario, Canada, ${ }^{4}$ Mount Sinai Hospital Division of Gastroenterology, University of Toronto, Toronto, Ontario, Canada, ${ }^{5}$ Johns Hopkins School of Medicine, Baltimore, Maryland, USA, ${ }^{6}$ Ecology and Epidemiology Group, Department of Biological Sciences, University of Warwick, Warwick, UK, ${ }^{7}$ Centre for Health Research in Criminal Justice, Sydney, Australia, ${ }^{8}$ School of Public Health and Community Medicine, The University of New South Wales, Sydney, Australia, ${ }^{9}$ Toronto Health Economics and Technology Assessment Collaborative, Department of Medicine Toronto, Ontario, Canada and ${ }^{10}$ National Centre in HIV Epidemiology and Clinical Research, The University of New South Wales, Sydney, Australia
\end{abstract}

Email: Christopher AKY Chong* - caky.chong@gmail.com; Sicong Li - sicong.li@utoronto.ca; Geoffrey C Nguyen - gnguyen@mtsinai.on.ca; Andrew Sutton - Andrew.Sutton@warwick.ac.uk; Michael H Levy - mrya@tpg.com.au; Tony Butler - tbutler2@optusnet.com.au; Murray D Krahn - murray.krahn@theta.utoronto.ca; Hla-Hla Thein - Rthein@nchecr.unsw.edu.au

* Corresponding author

Published: 28 August 2009

Health and Quality of Life Outcomes 2009, 7:78 doi:10.1 186/1477-7525-7-78
Received: 14 April 2009

Accepted: 28 August 2009

This article is available from: http://www.hqlo.com/content/7///78

(C) 2009 Chong et al; licensee BioMed Central Ltd.

This is an Open Access article distributed under the terms of the Creative Commons Attribution License (http://creativecommons.org/licenses/by/2.0), which permits unrestricted use, distribution, and reproduction in any medium, provided the original work is properly cited.

\begin{abstract}
Background: Health-state utilities for prisoners have not been described.

Methods: We used data from a 1996 cross-sectional survey of Australian prisoners $(n=734)$. Respondent-level SF-36 data was transformed into utility scores by both the SF-6D and Nichol's method. Socio-demographic and clinical predictors of SF-6D utility were assessed in univariate analyses and a multivariate general linear model.

Results: The overall mean SF-6D utility was 0.725 (SD 0.1 19). When subdivided by various medical conditions, prisoner SF-6D utilities ranged from 0.620 for angina to 0.764 for those with none/mild depressive symptoms. Utilities derived by the Nichol's method were higher than SF-6D scores, often by more than 0.1 . In multivariate analysis, significant independent predictors of worse utility included female gender, increasing age, increasing number of comorbidities and more severe depressive symptoms.
\end{abstract}

Conclusion: The utilities presented may prove useful for future economic and decision models evaluating prison-based health programs.

\section{Background}

Prisoners represent an understudied population in health care research although they have a disproportionately high prevalence of many illnesses. For example, the prevalence of a wide-range of psychiatric disorders is easily more than double than that found in the community [1]. About $2 \%$ of the U.S. general population test positive for the hepatitis $\mathrm{C}$ antibody, compared to 12 to $64 \%$ of prisoners [2]. In particular, few investigations have explored the health-related quality of life (HRQL) of prisoners. 
Understanding inmate HRQL is essential to developing effective prison health programs and policies.

To the best of our knowledge, HRQL measurements in the form of utilities have not been obtained in prisoners. A utility is a preference-based, global measurement of overall health on a scale of 0 to 1 , and is the most widely used method for evaluating HRQL in economic and decision analyses [3]. To date researchers have been limited to using utilities obtained from non-inmate populations $[4,5]$. However, the social, demographic, economic and health status of prisoners is clearly different from other groups $[1,2]$. Thus, specifically using inmate-based utilities could improve the validity and quality of economic and decision analyses that evaluate prison health programs.

The primary purpose of our study was to derive inmatebased utilities for use in future economic and decision models. Secondary objectives were to explore how sociodemographics and comorbidity affect prisoner HRQL and to compare different methods for deriving utilities.

\section{Methods \\ Survey}

Detailed methods of the survey have been published elsewhere [6]. Briefly, ethics approval was obtained from the Justice Health Human Ethics and Research Committee and the New South Wales (NSW) Department of Corrective Services Ethics Committee. In 1996, NSW Justice Health surveyed a cross-sectional random sample of prisoners from 27 male and two female correctional services, stratified for age, gender and indigenous origin. Participants were randomly chosen from a list of all inmates at each prison and those selected provided written consent; those that refused were replaced by inmates on a reserve list. Participants were compensated with \$A 10.

Study nurses conducted extensive face-to-face structured interviews and participants completed various health questionnaires. Information collected included: 1) standard socio-demographic characteristics. 2) Comorbidities, gathered as self-reported health conditions. The survey also assessed whether prescribed medications for certain chronic health conditions had been used in the preceding two weeks, allowing us to further confirm some selfreported diagnoses. 3) Hepatitis C viral infection (HCV) status. The original purpose of this survey included assessing the prevalence of bloodborne infections, and HCV antibody and viral polymerase chain reaction (PCR) status were obtained through standard laboratory testing [6]. 4) Beck Depression Inventory (BDI). The BDI is a wellestablished 21-item questionnaire that assesses depression severity in the preceding week, with higher scores indicating more severe symptoms. The scores can then be divided into none, mild, moderate or severe symptom groups [7]. 5) World Health Organization Alcohol Use Disorder level, which classifies alcohol consumption in safe, harmful or hazardous categories [8]. 6) Short-Form 36 (SF-36). The SF-36 is a very widely used non-preference based general health survey that measures HRQL during the previous four weeks over eight domains [9].

Of the 789 patients in the original study, 55 did not complete the SF-36. Because the main purpose of this study was to derive utilities and the SF-36 was necessary to do so (see below), these 55 were excluded from the analysis for a final sample size of 734 . The purpose of the original survey was to detect a range of health conditions from the NSW prisoner population and the sample size was thus chosen for that specific aim. The primary objective of this study is to provide an estimate of mean prisoner-based utilities; assuming an SF-6D standard deviation of 0.147 [10] and an acceptable error of 0.05 , the needed sample size would be 33 [11], which is comparable to the usual recommendation of 30 to 60 subjects for standard gamble utility studies [12].

\section{Deriving utilities}

Several methods exist for transforming SF-36 scores into utilities. These techniques attempt to translate the nonpreference-based SF-36 health description into an accepted preference-based utility measurement. Existing techniques allow translating the SF-36 description into the Visual Analogue Scale, Health Utilities Index, Quality of Well Being Scores or Standard Gamble, all of which are distinct forms of measuring utilities. We selected what we felt were the two most robust methods, the Nichol method [13] and the Brazier SF-6D method [14]. The different techniques are not meant to be averaged together.

In the Nichol method, the eight SF-36 domain scores are first transformed into norm-based scores that have been standardized to the 1998 general United States (US) population for a mean of 50 and a standard deviation of 10 . A regression equation developed from a sample of 6921 subjects is then applied to these eight scores to convert them into a Health Utilities Index II (HUI2) utility. The HUI2 is a multi-attribute health state classification system that defines 24000 hypothetical unique health states and assigns a utility to each one using preference scores derived from a survey of the general population [15]. The utilities are based on the standard gamble, which is arguably the utility scaling method with the strongest theoretical foundation [3]. The Nichol translation of SF-36 scores predicts $50.5 \%$ of the variance in HUI2 utilities. The range of possible utilities using this method is -0.03 to 1.00 .

Brazier's SF-6D method represents a more exact method of transforming SF-36 data into utilities. Respondent-level 
data from the SF-36 questions are first explicitly restructured into six health domains which describe 18000 health states. Using the standard gamble, 611 members of the United Kingdom (UK) general population valued a 249 subset of these states, and a model was then developed to define utilities for the full set. Of existing methods for converting SF-36 data into utilities, this technique may be the most robust as it uses respondent-level data to clearly define unique health states which have been directly valued by a general population. Like the HUI2, the SF-6D represents community derived preferences for health outcomes. The range of possible utilities based on this model is 0.30 to 1.00 .

\section{Analysis}

To compare the distribution of categorical variables, contingency chi square analysis was used. When appropriate, t-tests or one-way analysis of variance with post-hoc Tukey tests were used to compare means of continuous variables. Pearson and Spearman tests were used to examine correlations between continuous variables. Statistical significance was defined at $\mathrm{p}<0.05$.

To assess predictors of utilities, all the socio-demographic and clinical characteristics were first assessed for significance in univariate analysis. All characteristics were then correlated with one another to assess for collinearity. Most clinical factors were found to be collinear (e.g. subjects reporting one medical condition were more likely to also report another medical condition), making it difficult to enter them all as independent variables. We thus collapsed all the medical conditions into a single variable of comorbidity count. We considered depression (BDI score) separately from other comorbid illnesses, as we were particularly interested in the effect of mental health. Variables that were significant at $\mathrm{p}<0.10$ were then entered as covariates in a forward step-wise general linear regression model that included the forced variables of gender and age. Variables that continued to be significant at a twosided level of $\mathrm{p}<0.10$ were kept as main effects. Two-way interactions for the remaining variables were then assessed for significance.

All analyses were performed with SPSS version 16.0.

\section{Results}

\section{Socio-demographic characteristics}

Table 1 outlines the socio-demographic features of the 734 participants in the study. The prisoner population was predominantly young and male, with low education and pre-incarceration employment levels. Most had spent less than one year in prison. In the 55 subjects who were excluded because they did not complete the SF-36, there was a higher proportion of females $(29.1 \%$ vs. $15.8 \%$, $\mathrm{p}=$ $0.011)$ and Aboriginal people $(41.8 \%$ vs. $28.9 \%, \mathrm{p}=$ 0.043 ) than in those who did complete the SF-36.
Table I: Socio-demographic characteristics of prisoner respondents (total $\mathbf{n}=\mathbf{7 3 4}$ )

\begin{tabular}{ll}
\hline Characteristic & $\mathrm{n}$ (percentage) \\
\hline $\begin{array}{l}\text { Male } \\
\text { Age (years) }\end{array}$ & $618(84.2)$ \\
$\quad$ I8 - 24 & $242(33.0)$ \\
$25-39$ & $278(37.9)$ \\
$\geq 40$ & $214(29.2)$ \\
Aboriginal & $212(28.9)$ \\
Born in Australia & $595(81.1)$ \\
Time in jail (years) & \\
$\quad \leq$ I & $403(54.9)$ \\
$\quad>$ I to $\leq 5$ & $253(34.5)$ \\
$\quad>5$ & $78(10.6)$ \\
Marital status & \\
$\quad$ single & $273(37.2)$ \\
$\quad$ married/regular partner & $394(53.7)$ \\
Sexual identity & \\
$\quad$ Heterosexual & $640(87.2)$ \\
Working before entering prison & $314(42.8)$ \\
Educational status & \\
$\quad$ no formal qualification & $36 \mathrm{I}(49.2)$ \\
Accommodation before entering prison & \\
$\quad$ renting & \\
live with family/own home & $40 \mathrm{I}(54.6)$ \\
\end{tabular}

\section{Utilities}

The SF-6D and Nichol utilities for the entire sample stratified by various conditions are presented in Table 2. SF-6D utilities range from 0.620 for those reporting angina and using cardiac medication to 0.764 for those scoring none/ mild symptoms on the BDI. The Nichol estimated utilities are consistently higher than the SF-6D; the average paired mean difference is 0.122 (SD 0.059, $\mathrm{p}<0.001$ ). The two methods, are, however, highly correlated with a Spearman correlation of $0.898(\mathrm{p}<0.001)$.

In univariate analysis, prisoners had significantly lower SF-6D utilities with the following conditions than without the conditions ( $\mathrm{p} \leq 0.005$ for all): angina (delta utility $[\Delta]=-0.090)$, arthritis $(\Delta=-0.070)$, asthma $(\Delta=-0.048)$, back problems $(\Delta=-0.078)$, worse BDI score $(\Delta=-0.071$ for moderate vs. none/mild; $\Delta=-0.139$ for severe vs. none/mild), cholelithiasis $(\Delta=-0.093)$, epilepsy $(\Delta=-$ $0.057)$, hemorrhoids $(\Delta=-0.069)$, hypertension $(\Delta=$ $0.060)$, prison methadone program use $(\Delta=-0.043)$, peptic ulcer disease $(\Delta=-0.066)$, prostate condition $(\Delta=$ $0.069)$, and psychiatric medication use $(\Delta=-0.090)$. Selfreporters of hepatitis $B$ had lower scores approaching statistical significance $(\Delta=-0.024, \mathrm{p}=0.074)$. Harmful or hazardous alcohol consumption was not associated with significantly different scores $(\mathrm{p}=0.412)$. The remaining conditions that did not reach statistical significance (diabetes $\Delta=-0.025$, human immunodeficiency virus [HIV] $\Delta$ $=-0.059$, and kidney condition $\Delta=-0.004$ ) had 25 or fewer participants reporting the condition. 
Table 2: SF-6D and Nichol utilities for prisoner respondents by medical conditions.

\begin{tabular}{|c|c|c|c|}
\hline & $\mathrm{n}$ (percentage) & mean SF-6D utility (SD) & mean Nichol utility (SD) \\
\hline Total & $734(100)$ & $0.725(0.119)$ & $0.846(0.133)$ \\
\hline \multicolumn{4}{|l|}{ Alcohol use } \\
\hline harmfult & $282(38.4)$ & $0.732(0.115)$ & $0.854(0.129)$ \\
\hline \multicolumn{4}{|l|}{ Angina/chest pain } \\
\hline self-report & $81(11.0)$ & $0.644(0.131)$ & $0.742(0.161)$ \\
\hline self-report \& med* & $17(2.3)$ & $0.620(0.169)$ & $0.687(0.206)$ \\
\hline \multicolumn{4}{|l|}{ Arthritis } \\
\hline self-report & $120(16.3)$ & $0.666(0.116)$ & $0.772(0.137)$ \\
\hline \multicolumn{4}{|l|}{ Asthma } \\
\hline self-report & $153(20.8)$ & $0.687(0.122)$ & $0.796(0.142)$ \\
\hline self-report \& med* & $69(9.4)$ & $0.656(0.130)$ & $0.760(0.155)$ \\
\hline \multicolumn{4}{|l|}{ Back problems } \\
\hline self-report & $211(28.7)$ & $0.669(0.111)$ & $0.778(0.137)$ \\
\hline \multicolumn{4}{|l|}{ Beck Depression Inventory Score } \\
\hline none/minimal & $418(56.9)$ & $0.764(0.101)$ & $0.898(0.100)$ \\
\hline moderate & $153(20.8)$ & $0.693(0.113)$ & $0.813(0.118)$ \\
\hline severe & $120(16.3)$ & $0.625(0.106)$ & $0.714(0.132)$ \\
\hline \multicolumn{4}{|l|}{ Cholelithiasis } \\
\hline self-report & $28(3.8)$ & $0.635(0.140)$ & $0.740(0.168)$ \\
\hline \multicolumn{4}{|l|}{ Diabetes } \\
\hline self-report & $25(3.4)$ & $0.699(0.135)$ & $0.804(0.147)$ \\
\hline self-report \& med* & $12(1.6)$ & $0.724(0.157)$ & $0.831(0.175)$ \\
\hline \multicolumn{4}{|l|}{ Epilepsy } \\
\hline self-report & $36(4.9)$ & $0.670(0.113)$ & $0.789(0.148)$ \\
\hline self-report \& med* & $18(2.5)$ & $0.647(0.120)$ & $0.784(0.163)$ \\
\hline \multicolumn{4}{|l|}{ Haemorrhoids } \\
\hline self-report & $66(9.0)$ & $0.661(0.109)$ & $0.770(0.115)$ \\
\hline \multicolumn{4}{|l|}{ Hepatitis B } \\
\hline self-report & $87(11.9)$ & $0.703(0.119)$ & $0.815(0.135)$ \\
\hline \multicolumn{4}{|l|}{ Hepatitis C } \\
\hline self-report & $199(27.1)$ & $0.704(0.121)$ & $0.820(0.138)$ \\
\hline Ab positive/viremic & $178(24.3)$ & $0.719(0.119)$ & $0.839(0.133)$ \\
\hline correctly aware positive ${ }^{* *}$ & $127(17.3)$ & $0.709(0.120)$ & $0.824(0.137)$ \\
\hline unaware positive** & $51(6.9)$ & $0.744(0.116)$ & $0.879(0.112)$ \\
\hline correctly aware negative ${ }^{* *}$ & $417(56.8)$ & $0.729(0.118)$ & $0.852(0.134)$ \\
\hline falsely believe positive** & $5(0.7)$ & $0.809(0.029)$ & $0.924(0.085)$ \\
\hline \multicolumn{4}{|l|}{ HIV } \\
\hline self-report & $7(1.0)$ & $0.660(0.119)$ & $0.788(0.144)$ \\
\hline \multicolumn{4}{|l|}{ Hypertension } \\
\hline self-report & $93(12.7)$ & $0.672(0.129)$ & $0.782(0.155)$ \\
\hline self-report \& med* & $12(1.6)$ & $0.633(0.176)$ & $0.732(0.185)$ \\
\hline \multicolumn{4}{|l|}{ IV drug use } \\
\hline used in past year & $216(29.4)$ & $0.711(0.119)$ & $0.828(0.135)$ \\
\hline prison methadone program & $92(12.5)$ & $0.685(0.119)$ & $0.792(0.133)$ \\
\hline \multicolumn{4}{|l|}{ Kidney condition } \\
\hline self-report & II (I.5) & $0.721(0.124)$ & $0.793(0.183)$ \\
\hline \multicolumn{4}{|l|}{ Peptic ulcer } \\
\hline self-report & $70(9.5)$ & $0.665(0.129)$ & $0.769(0.151)$ \\
\hline self-report \& med* & $37(5.0)$ & $0.648(0.124)$ & $0.749(0.150)$ \\
\hline \multicolumn{4}{|l|}{ Prostate condition } \\
\hline self-report & $27(3.7)$ & $0.666(0.105)$ & $0.777(0.135)$ \\
\hline \multicolumn{4}{|l|}{ Psychiatric condition } \\
\hline took psychiatric med & $82(11.2)$ & $0.646(0.120)$ & $0.752(0.152)$ \\
\hline
\end{tabular}

tbased on WHO Alcohol Use Disorder Identification Test levels

*respondents who both self-reported the listed condition and took prescription medication for that specific illness in the past two weeks

**correctly aware positive = self-reported yes and antibody positive/viremic; unaware positive = did not self-report but antibody positive/viremic; correctly aware negative $=$ did not self-report and antibody negative; falsely believe positive $=$ self-reported yes but antibody negative. 
This study's original design allowed us to further explore the effect of being aware of HCV infection on HRQL. As a whole, those who were correctly aware of having active HCV infection trended towards worse SF-6D utilities than the remaining sample $(\Delta=-0.023, \mathrm{p}=0.053)$. However, those unaware of active infection trended towards better scores than those who were correctly aware of their hepatitis $C$ status $(\Delta=0.035, \mathrm{p}=0.079)$.

\section{Predictors of SF-6D utility}

In univariate analysis, sociodemographic factors which correlated with worse SF-6D utilities included increasing age, female gender, increasing time spent in jail and nonheterosexual identity ( $\mathrm{p} \leq 0.01$ for all). The results of a multivariate model including medical conditions are shown in Table 3. Increasing age and female gender were found to be independent predictors of lower utilities. Each additional medical illness resulted in an approximately - 0.03 decrement in utility. Each increase of 1.0 in BDI score was associated with an about -0.008 utility decrease. There was a significant interaction with worse BDI score and higher comorbidity count actually slightly increasing utility. This interaction thus functions as a correction factor to adjust utility scores upwards for subjects with both poor comorbidity and BDI scores. The multivariate model was repeated using the Nichol utilities with similar results, except the interaction between BDI score and comorbidity was not significant.

We further explored how many prisoners with psychological needs access mental health care, and found that of subjects in our sample reporting severe BDI scores, only $43.7 \%$ were receiving counselling and only $24.2 \%$ had been taking a prescription psychiatric medication

\section{Discussion}

Our main aim is to derive inmate-based health state utilities and our results do provide such values from a large, general prisoner population. Not surprisingly, the mean SF-6D utility (0.73) is lower than the average Australian population of 0.80 [16], as well as the average male US population aged 35 to 44 of 0.89 [17]. Such decrements of about 0.07 to 0.16 relative to the average population is a considerable amount of disutility, comparable in this study to the difference between having and not having arthritis (-0.070) or depression (-0.139). It is uncertain how much of this difference is secondary to the population's socio-demographic status, baseline number of comorbidities or effect of incarceration. The data contribute to an emerging body of literature describing the HRQL in this marginalized group. The utilities obtained may prove useful in future cost-effectiveness analyses of prisoner programs and help guide health policy.

In terms of directing health programs to issues most affecting prisoner HRQL, it is interesting that our multivariate analysis specially highlights the importance of gender and depressive symptoms. Other studies have also noted the particularly poor HRQL in female prisoners, and we agree with calls for women-oriented prison health programs $[18,19]$. Effective management of mental wellbeing is important in overall health and key to successfully returning to the community [1]. Given that participants in our sample did not frequently utilize counselling or psychiatric medications, opportunities would seem to exist to improve mental health care in jails.

The effect of psychology on HRQL is also illustrated in our specific analysis of prisoners with HCV. Similar to other research $[20,21]$, the simple knowledge of having HCV does appear to have a negative impact on HRQL above that from the infection itself. While it may be tempting to dismiss this effect as being entirely psychological, it must be noted that knowing one is infected constitutes part of the condition. The decrement in utility is thus valid and real. Improving prisoner understanding of HCV and increasing availability to treatment options is especially important in this population with highly prevalent HCV and poor baseline mental health.

With respect to the different methods of deriving utilities, we found the Nichol utilities to be consistently higher than the SF-6D, and we are unsure as to why. Studies of SF-36 derived utilities in patients undergoing total hip arthroplasty [22] and lung transplants [23] found similar results. The Nichol utility is based on the HUI2, which, like the SF-6D, is also based on the standard gamble. Cultural differences may be at play. For example, in one study of type 2 diabetics, Euro-Qol 5D index scores based on US weights were higher than UK ones [24]. Nichol utilities

Table 3: General linear regression model for demographic and clinical predictors of SF-6D utility in a prisoner population $(n=734)$

\begin{tabular}{lcc}
\hline Variable & Beta-estimate $(95 \%$ confidence interval) & $P$ value \\
\hline Intercept & $0.8605(0.8335,0.8874)$ & $<0.001$ \\
Age & $-0.0007(-0.0013,-0.0001)$ & 0.023 \\
Female & $-0.0253(-0.0462,-0.0193)$ & 0.018 \\
BDI score & $-0.0079(-0.0096,-0.0062)$ & $<0.001$ \\
comorbidity count & $-0.0281(-0.0370,-0.0193)$ & $<0.001$ \\
BDI score * comorbidity count & $0.0009(0.002,0.0015)$ & 0.009
\end{tabular}


are based on an American derivation as opposed to the UK SF-6D translation used in this study. From a methodological and theoretical standpoint, the respondent level SF-6D utilities are more robust than the Nichol translation. The presented utilities must be interpreted in the context of how they were derived as alternative techniques may have led to different results. The statistical significance of our findings may have changed had utilities been elicited in another manner. This study further illustrates how generic health utility instruments can range widely depending on the method of elicitation - which method to use can be controversial [3]. A more comprehensive, systematic analysis that compares the different techniques to obtain utilities from the SF-36 and other utility elicitation methods is warranted. For instance, it would be interesting to determine where the methods differ the most (e.g., low vs. high utility levels, ceiling and floor effects, responsiveness in various patient groups, etc.), although such analysis is beyond the scope of this paper.

Our study does have limitations. First, the prisoners who did not complete the SF-36 were significantly different in some socio-demographic features and thus their utilities may have also differed. However, the number of noncompleters was small. We were forced to rely on selfreport for diagnosing most health conditions, although when possible we also tried to corroborate this with prescription medication use. Finally, this study used data from 1996 and changes to correctional institutions since that affect health utilities may not be reflected in these scores.

\section{Conclusion}

To the best of our knowledge, this paper provides the first utilities directly obtained from a prisoner population. The values may help provide prison-based decision and costeffectiveness analyses with a stronger evidence base. This study highlights the importance of gender and depression on prisoner quality of life, and also how simple knowledge of HCV infection might worsen utilities. Such findings may have implications for directing prison-based health programs. Future research should include obtaining direct utilities from prisoners using standard techniques (e.g. standard gamble), replicating this study in a more current population, documenting changes in health status over time while incarcerated, exploring the HRQL impact of various prison-based health interventions and obtaining utilities from prisons in other countries.

\section{Abbreviations}

HRQL: Health-related quality of life; NSW: New South Wales; HCV: hepatitis C virus; PCR: polymerase chain reaction; BDI: Beck Depression Inventory; SF-36: ShortForm 36; HUI2: Health Utilities Index II; US: United
States; UK: United Kingdom; HIV: human immunodeficiency virus

\section{Competing interests}

The authors declare that they have no competing interests.

\section{Authors' contributions}

CAKYC was involved in study design, performed statistical analysis, interpreted the data and wrote the first draft. SL provided a literature review and helped draft the manuscript. GCN provided statistical support and early data interpretation, and helped draft and revise the paper. AS conceived the original idea for this paper and revised the manuscript. TB and MHL were involved in the original survey used in this paper, provided the original data and revised the manuscript. MDK was involved in data interpretation and manuscript revision. HT was involved in study design, data organization, early data interpretation and manuscript revision. All authors read and approved the final manuscript.

\section{Acknowledgements}

The original survey used for this study [6] was financially supported by the NSW Corrections Health Service and the NSW Health Department. Lakeridge Health Oshawa financially supports Open Access fees for this manuscript.

\section{References}

I. White $\mathrm{P}$, Whiteford $\mathrm{H}$ : Prisons: mental health institutions of the 2 I st century? MJA 2006, I85:302-303.

2. Sterling RK, Brown RS Jr, Hofmann CM, Luketic VA, Stravitz RT, Sanyal AG, Contos MJ, Mills AS, Smith V, Shiffman ML: The spectrum of chronic hepatitis $C$ virus infection in the Virginia correctional system: development of a strategy for the evaluation and treatment of inmates with HCV. Am J Gastroenterol 2005, 100:3|3-32I.

3. Gold MR, Siegel JE, Russell LB, Weinstein MC: Cost-effectiveness in health and medicine New York: Oxford University Press; 1996.

4. Aoki N, Dunn K, Fukui T, Beck JR, Schull WJ, Li HK: Cost-effectiveness analysis of telemedicine to evaluate diabetic retinopathy in a prisoner population. Diab Care 2004, 27: 1095-I I0I.

5. Sutton AJ, Edmunds WJ, Sweeting MJ, Gill ON: The cost-effectiveness of screening and treatment for hepatitis $C$ in prisons in England and Wales: a cost-utility analysis. J Viral Hepat 2008, 15:797-808.

6. Butler T: Preliminary findings of the NSW Inmate Health Survey NSW: NSW Corrections Health Service; 1997.

7. Beck AT, Rush AJ, Shaw BF, Emery G: Cognitive Therapy of Depression NewYork: Guildford; 1979.

8. Babor TF, Higgins-Biddle JC, Saunders JB, Monteiro MG: The Alcohol Use Disorders Identification Test. Guidelines for Use in Primary Care 2nd edition. Geneva: World Health Organization; 200I.

9. Ware JE Jr, Sherbourne CD: The MOS 36-item short-form health survey (SF-36): I. Conceptual framework and item selection. Med Care 1992, 30:473-483.

10. Petrou S, Hockley C: An investigation into the empirical validity of the EQ-5D and SF-6D based on hypothetical preferences in a general population. Health Econ 2005, 14:1 I69-1 189.

II. Zar JH: Biostatistical Analysis Upper Saddle River: Simon \& Schuster; 1996.

12. Maetzel A, Krahn M, Naglie G: The cost-effectiveness of celecoxib and rofecoxib in patients with osteoarthritis or rheumatoid arthritis. Ottawa: Canadian Coordinating Office for Health Technology Assessment; 200I. Technology report no 23

13. Nichol MD, Sengupta N, Globe DR: Evaluating quality-adjusted life years: Estimation of the health utility index (HUI2) from the SF-36. Med Decis Making 200I, 21:105-II2. 
14. Brazier JE, Roberts JR, Deverill M: The estimation of a preference-based measure of health from the SF-36. J Health Econ 2002, $21: 27 \mid-292$.

15. Torrance GW, Feeny DH, Furlong WJ, Barr RD, Zhang Y, Wang Q: Multi-Attribute Preference Functions for A Comprehensive Health Status Classification System: Health Utilities Index Mark 2. Med Care 1996, 34:702-722.

16. Lee BB, King MT, Simpson JM, Haran MJ, Stockler MR, Marial O, Salkeld G: Validity, responsiveness, and minimal important difference for the SF-6D health utility scale in a spinal cord injured population. Value Health 2008, I I :680-688.

17. Fryback DG, Dunham NC, Palta M, Hammer J, Buechner J, Cherepanov D, Herrington SA, Hays RD, Kaplan RM, Ganiats TG Feeny $D$, Kind $P$ : US Norms for six generic health-related quality-of-life indexes from the National Health Measurement Study. Med Care 2007, 45: I 162-1170.

18. Plugge E, Fitzpatrick R: Assessing the health of women in prison: A study from the United Kingdom. Health Care Women Int 2005, 26:62-68.

19. Mooney M, Hannon F, Barry M, Friel S, Kelleher C: Perceived quality of life and mental health status of Irish female prisoners. Ir Med J 2002, 95:24I-243.

20. Thein HH, Butler T, Krahn M, Rawlinson W, Levy MH, Kaldor JM, Dore GJ: The effect of hepatitis $C$ virus infection on healthrelated quality of life in prisoners. J Urban Health 2006 , 83:275-288.

21. Rodger AJ, Jolley D, Thompson SC, Lanigan A, Crofts N: The impact of diagnosis of hepatitis $\mathbf{C}$ virus on quality of life. Hepatology 1999, 30:1299-1301.

22. Feeny $D$, Eng $K$ : Comparing utility scores derived from the Short-Form 36, standard gamble and Health Utilities Index. Institute of Health Economics Working Paper 04-05; 2004.

23. Lobo FS, Gross CR, Matthees BJ: Estimation and comparison of derived preference scores from the SF-36 in lung transplant patients. Quality of Life Research 2004, I3:377-388.

24. Sakthong $P$, Charoenvisuthiwongs $R$, Shabunthom $R$ : A comparison of EQ-5D index scores using the UK, US and Japan preference weights in a Thai sample with type 2 diabetes. Health Qual Life Outcomes 2008, 6:71.
Publish with Bio Med Central and every scientist can read your work free of charge

"BioMed Central will be the most significant development for disseminating the results of biomedical research in our lifetime. "

Sir Paul Nurse, Cancer Research UK

Your research papers will be:

- available free of charge to the entire biomedical community

- peer reviewed and published immediately upon acceptance

- cited in PubMed and archived on PubMed Central

- yours - you keep the copyright
BioMedcentral 